\title{
GAMBARAN GULA DARAH PADA LANSIA DI PANTI SOSIAL TRESNA WREDHA WANA SRAYA DENPASAR DAN PANTI SOSIAL WREDHA SANTI TABANAN
}

\author{
DESCRIPTION OF BLOOD SUGAR IN ELDERLY IN \\ NURSING HOME WANA SRAYA DENPASAR AND IN \\ NURSING HOME SANTI TABANAN
}

\author{
Yudiana Putra, IG. \\ Program Studi DIII Keperawatan, Akademi Keperawatan Kesdam IX/Udayana
}

\begin{abstract}
ABSTRAK
Penyakit yang sering ditemui pada lansia adalah diabetes mellitus. Diabetes melitus ditandai oleh adanya hiperglikemia kronik akibat efek kerja maupun sekresi insulin. Apabila diabetes mellitus tidak dikelola dengan baik dapat menimbulkan berbagai komplikasi yang dapat memperburuk kesehatan. Penelitian ini bertujuan untuk mengetahui Gambaran Gula Darah Sewaktu Pada Lansia Di Panti Sosial Tresna Wredha Wana Sraya Denpasar Dan Panti Sosial Wredha Santi Tabanan Rancangan penelitian yang digunakan metode deskriptif. Lokasi penelitian dilakukan di Panti Sosial Tresna Wredha Wana Sraya Denpasar Dan Panti Sosial Wredha Santi Tabanan. Jumlah populasi 50 responden, dengan 11 responden tidak memenuhi kriteria sehingga terdapat 39 responden. Instrumen Penelitian ini adalah lembar observasi, alat Easytouch dan stik gula darah untuk mengukur kadar gula darah sewaktu. Pengolahan data dilakukan dengan menggunakan komputerisasi. Data disajikan secara tekstular dan disertai dengan tabel. Pengukuran gula darah sewaktu menunjukkan 24 responden (61,54\%), dengan katagori belum pasti DM (100-199 mg/dl); 11 responden $(28,21 \%)$ dengan katagori bukan $\mathrm{DM}(<100 \mathrm{mg} / \mathrm{dl})$, sedangkan 4 responden $(10,25 \%)$ menunjukkan katagori DM ( $>200 \mathrm{mg} / \mathrm{dl})$. Nilai rata - rata gula darah sewaktu pada 39 responden adalah $140,025 \mathrm{mg} / \mathrm{dl}$. Sebagian besar lansia menunjukkan hasil pemeriksaan gula darah sewaktu dengan katagori belum pasti DM sebanyak 24 responden, dengan rentang hasil pemeriksaan $100-199 \mathrm{mg} / \mathrm{dl}$.
\end{abstract}

Kata kunci: Gula Darah Sewaktu, Lansia, Deskriptif

\section{ABSTRACT}

Disease that is often found in the elderly is diabetes mellitus. Diabetes mellitus is characterized by chronic hyperglycemia due to work effects or insulin secretion. If diabetes mellitus cannot be treated, it can help overcome complications that can worsen health. This study aims to determine the description of random blood sugar at the elderly in in social institution elderly wana sraya denpasar and the social institution elderly santi tabanan. The study design used descriptive method. The research location at social institution 
elderly wana sraya denpasar and the social institution elderly santi tabanan. Total population of 50 respondents, with 11 respondents did not meet the criteria so that there were 39 respondents. The research instrument was an observation sheet, Easytouch tool and blood sugar sticks to measure random blood sugar. Data processing is done using computerization. Data is presented in a textual and is accompanied by a table. Measurement of random blood sugar showing 24 respondents (61.54\%), with uncertain DM category (100-199 mg / dl); 11 respondents (28.21\%) with non-DM categories $(<100$ $\mathrm{mg} / \mathrm{dl}$ ), while 4 respondents $(10.25 \%)$ showed DM categories (> $200 \mathrm{mg} / \mathrm{dl})$. The average value of blood sugar at 39 respondents was $140.025 \mathrm{mg} / \mathrm{dl}$.Most of the elderly showed the results of random blood sugar with the category of uncertainty for DM as many as 24 respondents, with a range of examination results 100-199 $\mathrm{mg} / \mathrm{dl}$.

Keywords: Random Blood Sugar, Elderly, Descriptive

\author{
Alamat Korespondensi : Akademi Keperawatan Kesdam IX/Udayana \\ Email : yudianakesdam@gmail.com
}

\title{
PENDAHULUAN
}

Proses penuaan merupakan siklus kehidupan yang ditandai dengan tahapan menurunnya berbagai fungsi organ dalam tubuh yang ditandai dengan rentannya tubuh terhadap berbagai serangan penyakit. Hal tersebut disebabkan karena seiring meningkatnya usia, terjadi perubahan dalam struktur dan fungsi pada sel, jaringan serta sistem organ. Perubahan tersebut mempengaruhi kemunduran kesehatan fisik yang pada akhirnya akan berpengaruh pada kerentanan terhadap penyakit. (Nasrullah, 2016).

Masalah kesehatan yang banyak ditemukan akibat dari proses menua adalah diabetes mellitus. Masalah kesehatan ini sering di temui pada lansia karena terjadinya penurunan fungsi organ tubuh jantung, hati, dan ginjal serta peningkatan fungsi organ tubuh pada lansia akibat berkurangnya jumlah kemampuan sel tubuh (Fatmah, 2010).

Diabetes Melitus yang merupakan salah satu dari lima kondisi kronis paling utama yang mempengaruhi lansia. Diabetes militus adalah penyakit yang di tandai dengan kadar glukosa yang berlebih atau melebihi normal (hiperglikemia) di akibatkan oleh tubuh yang kekurangan insulin baik absolut maupun relatif, (H.R. DR. Hasdianah, 2012). Menurut internasional Of Diabetic Ferderation (IDF) di tahun 2012 menunjukkan bahwa China merupakan negara dengan prevalensi diabetes tertinggi di dunia dengan jumlah penderita mencapai 92,3 juta jiwa. Berdasarkan data survelensi terpandu penyakit (STP) prevalensi DM di Bali pada Tahun 2014 sebanyak 5,9\% dan kabupaten Gianyar termasuk 5 besar lansia DM di bali dengan jumblah 1.770 jiwa (Dinkes Provinsi Bali, 2015).

Apabila diabetes melitus tidak dikelola dengan baik dapat menimbulkan berbagai komplikasi yang dapat mengancam kehidupan. Bila tidak ditangani, komplikasi Diabetes Mellitus dapat menyerang seluruh anggota tubuh seperti gangguan pembuluh darah otak (stroke), pembuluh darah mata (retinopati, gangguan penglihatan), pembuluh darah jantung (penyakit jantung koroner), pembuluh darah ginjal (gagal ginjal), dan pada pembuluh darah kaki (luka yang sukar (luka yang sukar sembuh/ganggren) (Putri, NK dan Isfandiari, 2013) 
Tujuan Penelitian: Mengetahui Gambaran Tekanan Darah dan Gula Darah Sewaktu pada Lansia di Panti Sosial Tresna Wredha Wana Sraya Denpasar dan Panti Sosial Wredha Santi Tabanan.

\section{METODE PENELITIAN}

Jenis penelitian yang digunakan adalah metode deskriptif. Lokasi penelitian dilakukan di Panti Sosial Tresna Wredha Wana Sraya Denpasar dan di Panti Sosial Wredha Santi Tabanan. Teknik pengambilan sampel adalah Purposive Sampling. Dari total populasi yang berjumlah 50 lansia terdapat 11 lansia yang tidak memenuhi kreteria inklusi diantaranya lansia yang mengalami gangguan kejiwaan dan lansia yang tidak bersedia menjadi responden, sehingga jumlah sampel dalam penelitian ini yaitu sebanyak 39 responden. Instrumen Penelitian ini adalah lembar observasi, serta alat Easytouch dan stik gula darah untuk mengukur kadar gula darah sewaktu. Pengumpulan Data yang berupa data primer dan data sekunder. Data dikumpulkan melalui prosedur berikut ini: Melaksanakan pendekatan kepada subyek penelitian; Menjelaskan maksud dan tujuan penelitian; Memastikan legalitas persetujuan dengan surat persetujuan menjadi subyek penelitian; Menentukan sampel dengan teknik samplimg; Mengobservasi responden dengan lembar observasi; Mengukur tekanan darah dan gula darah sewaktu; Mencatat hasil pengukuran; Melakukan pengolahan data. Pengolahan data dilakukan dengan menggunakan komputerisasi. Data disajikan secara tekstular dan disertai dengan tabel.

\section{HASIL DAN PEMBAHASAN}

HASIL PENELITIAN

Tabel 1 Karakteristik Responden di Panti Sosial Tresna Wredha Wana Sraya Denpasar dan Panti Sosial Wredha Santi Tabanan

\begin{tabular}{lcc}
\hline \multicolumn{1}{c}{ Variabel } & Jumlah & Persentase (\%) \\
\hline Jenis Kelamin & & \\
$\quad$ Laki - laki & 10 & 25,64 \\
$\quad$ Perempuan & 29 & 74,36 \\
Kelompok Umur (Tahun) & & \\
$\quad$ Usia Pertengahan $(45-59)$ & 4 & 10,26 \\
$\quad$ Lanjut Usia $(60-74)$ & 14 & 35,90 \\
Lanjut Usia Tua $(75-90)$ & 20 & 51,28 \\
Usia Sangat Tua $(>90)$ & 1 & 2,56 \\
Tingkat Pendidkan & & \\
Tidak Sekolah & 26 & 66,67 \\
SD & 10 & 25,64 \\
SMP & 1 & 2,56 \\
SMA & 2 & 5,13 \\
\hline Total & $\mathbf{3 9}$ & $\mathbf{1 0 0}$ \\
\hline
\end{tabular}

Sumber: Data Primer 
Tabel 2. Hasil Pengukuran Gula Darah Sewaktu

\begin{tabular}{|c|c|c|c|c|c|c|}
\hline \multicolumn{3}{|c|}{ Katagori } & \multicolumn{2}{|c|}{ Jumlah } & \multicolumn{2}{|c|}{ Persentase (\%) } \\
\hline \multicolumn{7}{|c|}{ Gula Darah Sewaktu } \\
\hline \multicolumn{3}{|c|}{ Bukan DM: $<100 \mathrm{mg} / \mathrm{dl}$} & \multicolumn{2}{|c|}{11} & \multicolumn{2}{|c|}{28,21} \\
\hline \multicolumn{3}{|c|}{ Belum Pasti DM: $100-199 \mathrm{mg} / \mathrm{dl}$} & \multicolumn{2}{|c|}{24} & \multicolumn{2}{|c|}{61,54} \\
\hline \multicolumn{3}{|c|}{$\mathrm{DM}: \geq 200 \mathrm{mg} / \mathrm{dl}$} & \multicolumn{2}{|c|}{4} & \multicolumn{2}{|c|}{10,25} \\
\hline \multicolumn{3}{|l|}{ Total } & \multicolumn{2}{|c|}{39} & \multicolumn{2}{|c|}{100} \\
\hline \multicolumn{7}{|l|}{ Sumber : Data Primer } \\
\hline \multicolumn{7}{|c|}{ Tabel 3. Distribusi Frekuensi Gula Darah Sewaktu Berdasarkan Jenis Kelamin } \\
\hline \multirow[t]{2}{*}{ Jenis Kelamin } & \multicolumn{2}{|c|}{$\begin{array}{c}\text { Bukan DM: }<100 \\
\text { mg/dl }\end{array}$} & \multicolumn{2}{|c|}{$\begin{array}{c}\text { Belum Pasti } \\
\text { DM: } 100-199 \\
\text { mg/dl }\end{array}$} & \multicolumn{2}{|c|}{$\begin{array}{c}\mathrm{DM}: \geq 200 \\
\mathrm{mg} / \mathrm{dl}\end{array}$} \\
\hline & $\mathrm{f}$ & $\%$ & $\mathrm{f}$ & $\%$ & $\mathrm{f}$ & $\%$ \\
\hline Laki - Laki & 3 & 27,27 & 6 & 25 & 1 & 25 \\
\hline Perempuan & 8 & 72,73 & 18 & 75 & 3 & 75 \\
\hline Total & 11 & 100 & 24 & 100 & 4 & 100 \\
\hline
\end{tabular}

Sumber : Data Primer

Tabel 4. Distribusi Frekuensi Gula Darah Sewaktu Berdasarkan Kelompok Umur

\begin{tabular}{|c|c|c|c|c|c|c|}
\hline \multirow[t]{2}{*}{ Umur } & \multicolumn{2}{|c|}{$\begin{array}{c}\text { Bukan DM: < } \\
100 \mathrm{mg} / \mathrm{dl}\end{array}$} & \multicolumn{2}{|c|}{$\begin{array}{c}\text { Belum Pasti } \\
\text { DM: } 100-199 \\
\text { mg/dl }\end{array}$} & \multicolumn{2}{|c|}{$\begin{array}{c}\mathrm{DM}: \geq 200 \\
\mathrm{mg} / \mathrm{dl}\end{array}$} \\
\hline & $\mathrm{f}$ & $\%$ & $\mathrm{f}$ & $\%$ & $\mathrm{f}$ & $\%$ \\
\hline $\begin{array}{l}\text { Usia Pertengahan (45 - } \\
59 \text { ) }\end{array}$ & 4 & 36,37 & & & & \\
\hline Lanjut Usia $(60-74)$ & 3 & 27,27 & 8 & 33,33 & 3 & 75 \\
\hline $\begin{array}{l}\text { Lanjut Usia Tua (75 - } \\
90)\end{array}$ & 3 & 27,27 & 16 & 66,67 & 1 & 25 \\
\hline Usia Sangat Tua $(>90)$ & 1 & 9,09 & & & & \\
\hline Total & 11 & 100 & 24 & 100 & 4 & 100 \\
\hline
\end{tabular}

Sumber : Data Primer

\section{PEMBAHASAN}

Dari hasil penelitian pengukuran gula darah sewaktu menunjukkan 24 responden (61,54\%), dengan katagori belum pasti DM (100-199 mg/dl), 11 responden $(28,21 \%)$ dengan katagori bukan DM $(<100 \mathrm{mg} / \mathrm{dl})$, sedangkan 4 responden $(10,25 \%)$, menunjukkan katagori DM $(>200 \mathrm{mg} / \mathrm{dl})$. Nilai rata - rata gula darah sewaktu pada 39 responden adalah 140,025 mg/dl dengan katagori Belum pasti DM. Penelitian yang dilakukan oleh Hayyumahdania R, Yustini A, Rauza S pada tahun 2017 ditemukan lansia yang memenuhi kriteria diabetes sebanyak 4 orang $(14,81 \%)$ dan lansia yang memiliki glukosa normal sebanyak 23 orang (85,19\%). Begitu pula penelitian Rosyada dan Trihandini tahun 2013 yang dilakukan pada poliklinik lansia Puskesmas Kecamatan Jatinegara ditemukan lansia yang masuk kedalam kriteria diabetes melitus sekitar 35,5\%.11 Hal ini disebabkan 
karena sekitar 50\% lansia mengalami gangguan pada metabolisme glukosa sehingga lansia cenderung mengalami peningkatan glukosa darah.

Distribusi frekuensi gula darah sewaktu berdasarkan jenis kelamin didapatkan lansia laki-laki dengan katagori bukan DM sebanyak 3 responden (27.27\%), katagori belum pasti DM sebanyak 6 responden (25\%), katagori DM sebanyak 1 responden (25\%), sedangkan lansia perempuan dengan katagori bukan DM sebanyak 8 responden $(72.73 \%)$, katagori belum pasti DM sebanyak 18 responden (75\%), katagori DM sebanyak 3 responden (75\%). Terlihat dari hasil tersebut lansia perempuan cenderung mempunyai gula darah sewaktu lebih tinggi dari lansia laki- laki. Jenis kelamin mempengaruhi kadar gula darah karena perubahan persentase komposisi lemak tubuh pada lansia perempuan lebih tinggi daripada lansia laki-laki yang dapat menurunkan sensitifitas insulin. Perubahan komposisi lemak pada wanita yang telah menopouse terjadi karena penurunan kadar hormon estrogen dan progesteron. Apabila hormon estrogen dan progesteron menurun penggunaan lemak pada lansia wanita menjadi berkurang. (Darmojo, 2009)

Distribusi frekuensi gula darah sewaktu berdasarkan kelompok umur menunjukkan kelompok usia pertengahan (45-59 tahun) dengan 4 responden (36,37\%) bukan DM; kelompok Lanjut usia (60-74 tahun) menunjukkan 3 responden $(27,27 \%)$ bukan DM, 8 responden $(33.33 \%)$ belum pasti DM, 3 responden (75\%) DM; kelompok lanjut usia tua (75-90 tahun) menunjukkan 3 responden $(27,27 \%)$ bukan DM, 16 responden $(66,67 \%)$ belum pasti DM, 1 responden (25\%) DM; kelompok usia sangat tua ( $>90)$ menunjukkan 1 responden $(9,09 \%)$ Bukan DM. Terlihat dari hasil tersebut kelompok lanjut usia tua (75-90 tahun) mempunyai gula darah sewaktu lebih tinggi dibandingkan kelompok umur lainnya. Terlihat juga terjadinya peningkatan gula darah sewaktu seiring pertambahan umur. Umur merupakan salah satu faktor mandiri terhadap peningkatan gula darah. Semakin tua usia seseorang maka risiko peningkatan kadar glukosa darah dan gangguan toleransi glukosa akan semakin tinggi. Hal ini disebabkan oleh melemahnya semua fungsi organ tubuh termasuk sel pankreas yang bertugas menghasilkan insulin. Sel pankreas bisa mengalami degradasi yang menyebabkan hormon insulin yang dihasilkan terlalu sedikit sehingga kadar gula darah menjadi tinggi. Peningkatan kadar gula darah juga dapat disebabkan karena terganggunya homeostasis pengaturan gula darah. Gangguan pengaturan gula darah pada lansia meliputi tiga hal yaitu resistensi insulin, hilangnya pelepasan insulin fase pertama, dan peningkatan kadar gula darah postprandial. (Rochmah, 2009). Selain faktor usia terdapat faktor lain yang bisa mempengaruhi kadar gula darah pada lansia seperti asupan makanan, aktivitas fisik, obat-obatan, pengetahuan, pendidikan dan keterpaparan terhadap sumber informasi.

\section{SIMPULAN DAN SARAN}

Pengukuran gula darah sewaktu menunjukkan 24 responden $(61,54 \%)$, dengan katagori belum pasti DM (100-199 mg/dl) sedangkan 4 responden $(10,25 \%)$, menunjukkan katagori DM ( $>200 \mathrm{mg} / \mathrm{dl})$. Nilai rata - rata gula darah sewaktu pada 39 responden adalah 140,025 mg/dl; Distribusi frekuensi gula darah sewaktu berdasarkan jenis kelamin menunjukkan lansia perempuan cenderung mempunyai gula darah sewaktu lebih tinggi dari lansia laki- laki; Distribusi 
frekuensi gula darah sewaktu berdasarkan kelompok umur menunjukkan kelompok lanjut usia tua (75-90 tahun) mempunyai gula darah sewaktu lebih tinggi dibandingkan kelompok umur lainnya.

Diharapkan Pengelola Panti Sosial Tresna Wredha Wana Sraya Denpasar dan Panti Sosial Wredha Santi agar selalu memperhatikan keadaan kesehatan lansia; Diharapkan adanya pemantauan/pengukuran gula darah sewaktu secara konsisten; Diharapkan lansia dapat melakukan olahraga ringan secara teratur dan meningkatkan aktivitas fisik seperti berkebun, atau melakukan hobi yang disukai; Bagi Institusi Pendidikan melalui Hasil penelitian ini di harapkan dapat memberikan informasi ilmiah yang bermanfaat bagi mahasiswa dan dosen.

\section{UCAPAN TERIMAKASIH}

Puji Syukur penulis panjatkan kehadirat Ida Sang Hyang Widhi Wasa (Tuhan Yang Maha Esa) karena atas berkat dan rahmat-Nya penulis dapat menyelesaikan laporan penelitian ini tepat pada waktunya. Pada kesempatan ini penulis mengucapkan terima kasih kepada: Kepala dan Staff Panti Sosial Tresna Wredha Wana Sraya Denpasar dan Panti Sosial Wredha Santi Tabanan atas ijin dan bantuan yang diberikan untuk bisa melakukan penelitian ini; Semua pihak yang tidak bisa kami sebutkan satu per satu yang telah membantu kami guna kelancaran dari pelaksanaan kuliah lapangan dan penulisan laporan ini.

\section{DAFTAR PUSTAKA}

Darmojo B. Buku Ajar geriatri (ilmu kesehatan usia lanjut). Edisi ke-4. Jakarta: Balai Penerbit Fakultas Kedokteran Universitas Indonesia; 2009

Dinas Kesehatan Provinsi Bali. 2015. Profil Kesehatan Provinsi Bali. Provinsi Bali

Fatimah, R. N. 2015. Diabetes Militus Tipe II. Jurnal Majority, 4, 93-101.

Hasdianah H, R, D. 2012. Mengenal Diabetes Militus Pada Orang Dewasa Dan Anak-Anak Dengan Solusi Herba. Jakarta.

Hayyumahdania Reswan, Yustini Alioes, Rauza Sukma Rita. 2017. Gambaran Glukosa Darah pada Lansia di Panti Sosial Tresna Werdha Sabai Nan Aluih Sicinci.Jurnal Kesehatan Andalas. Vol.3, No., ISSN:230-7406

Internasional Diabetes Federation (IDF). 2014. Diabetic Atlas (Serial Online). Diunduh dari http://.idf.org/idf-diabetes-atlas-seventh-edition. Di unduh 25 Januari 2019.

Nasrullah, D. 2016. Buku Ajar Keperawatan Gerontik. Jakarta Timur: CV. Trans Info Media.

Putri, Nurlaili Kurnia Putri; Isfandiari, M. A. (2013). Hubungan empat pilar pengendalian dm tipe 2 dengan rerata kadar gula darah. Jurnal Berkala Epidemiologi, 1(2), 234-243.

Rochmah W. Diabetes melitus pada usia lanjut. Dalam: Sudoyo AW, Setiyohadi B, Alwi I, K Simadibrata M, Setiadi S, editor (penyunting). Buku ajar ilmu penyakit dalam. Edisi ke-5. Jakarta: Interna Publishing;2009 